\title{
Proposed Red Plan to Secure Project in PRINCE2 Methodology at Premature Closing Decision Situation
}

\author{
Umar Ali ${ }^{1}$, Cenk Calis ${ }^{2}$ \\ TTG International Ltd., Turkey ${ }^{1,2}$
}

\begin{abstract}
In this paper, the optimal decision model is developed to secure project. The model is described using Red Plan (RP) in PRINCE2 ("Projects IN Controlled Environments") approach. RP provides the significantly vivid estimation of loss comparison and helps to choose best way in Premature Closing Decision Situation (PCDS) time. However, the strategy of optimal decision to secure project has been proven by using RP which reduce the loss probability even in high threat open risk availability. The suggested model helps decision makers to assess optimal way before premature closing of the project.
\end{abstract}

Keywords: Loss comparison, PRINCE2, planning, risk, secure project

\section{Introduction}

PRINCE2 is the leading project management method in UK and becoming popular across the globe in both public and private sector [1]. In 1989, PRINCE2 is introduced by CCTA (the Central Computer and Telecommunications Agency) which has been very use full method in tracking and planning the project progress [8]. It has been developed to establish progression, control the commencement and termination the project. PRINCE2 is the generic method that can be used for any type of the project. It considers six performance parameters: Scope, Benefits, Risk, Timescales, Costs and Quality. It consists of four integrated elements or parts that are Principles, Themes, Processes and Tailoring.

The most difficult situation for the Project Board is to take decision of premature close of the project if business justification is no more valid. Mainly, the literature state that the decision of the company is based on what idea and project to develop is the matter of scheduling, planning and priori portfolio composition [2,11]. Thus, a suitable set of tools and methods, integrated in sequential and formal decision-making process, should lead to best decision $[3,4]$.

Basically, PRINCE2 offers 3 plans that consists of Project Plan, Stage Plan \& Team Plan. Exception Plan is used when stage forecast is to go out of tolerance and to recover from the effect of tolerance deviation. In this paper, we propose RF based solution to prevent investment loss in Premature Closing Decision Situation (PCDS) in Customer/Supplier environment.

\section{Basic Concepts}

Concept of the RP is planning in critical situation when Project Board has to decide for premature closing of the project. In this section we briefly present some fundamental ideas.

As discussed before, basically, PRINCE2 offers three plans Project Plan, Stage Plan \& Team Plan [5]. Also, Exception Plan and Red Plan have been described in this section with planning levels as shown in fig 1.1. 
A. Project Plan: It describes major products, resources and activities required for the project. It's a high-level plan and provide the knowledge of how and when a project's time, scope, cost and quality targets are to be achieved. The essential part of the Project Plan is cost and timescale.

B. Stage Plan: it defines day-to-day basis plan in detail which is required to create near the end of the current management stage. Project Manager is responsible to control and monitor the stage by using this detail plan.

C. Team Plan: Team Manager creates this optional plan which depends on complexity, project's size, and the required number of resources. Furthermore, PRINCE2 doesn't offer any format for team plan but Project Manager authorizes to review this Plan.

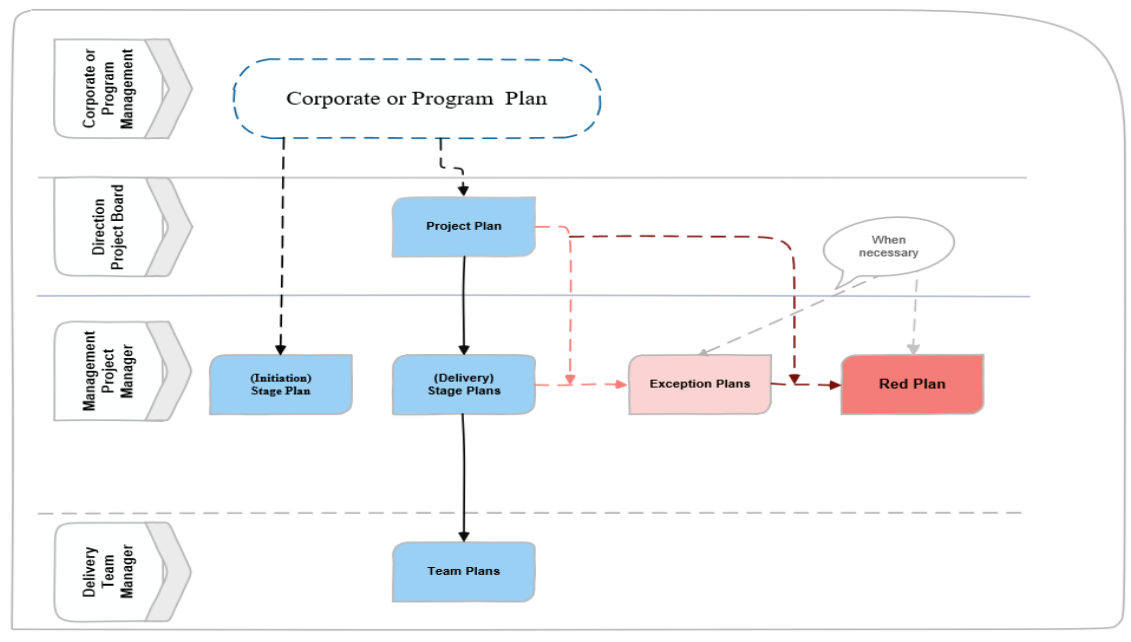

Fig 1.1

- Exception Plan: It is alternative to stage plan that creates only when deviation of stage tolerance is predicted to be increased. Project Manager is responsible to create and replace current stage plan. The purpose of this plan is to recover the stage from consequences of tolerance deviation. Furthermore, if the Work Package (WP) predict is exceeds the tolerance in future then Team Manager raises an issue to Project Manager. These issues can be resolved by creating a new WP or taking corrective action by updating the WP.

- Red Plan: The basic purpose of this proposed plan is to reduce or prevent the total investment loss in the project. Project Board must notify to Corporate or Program Management before giving order to Project Manager to create Red Plan. After creating the RP, Project Manager will request to Project Board for approval as illustrated in the figure 1.2. The objective of the RP is the comparison between loss of premature close of project and project completion loss in term of cost and time.

So, Project Board can evaluate both conditions from RP with updated business case. 


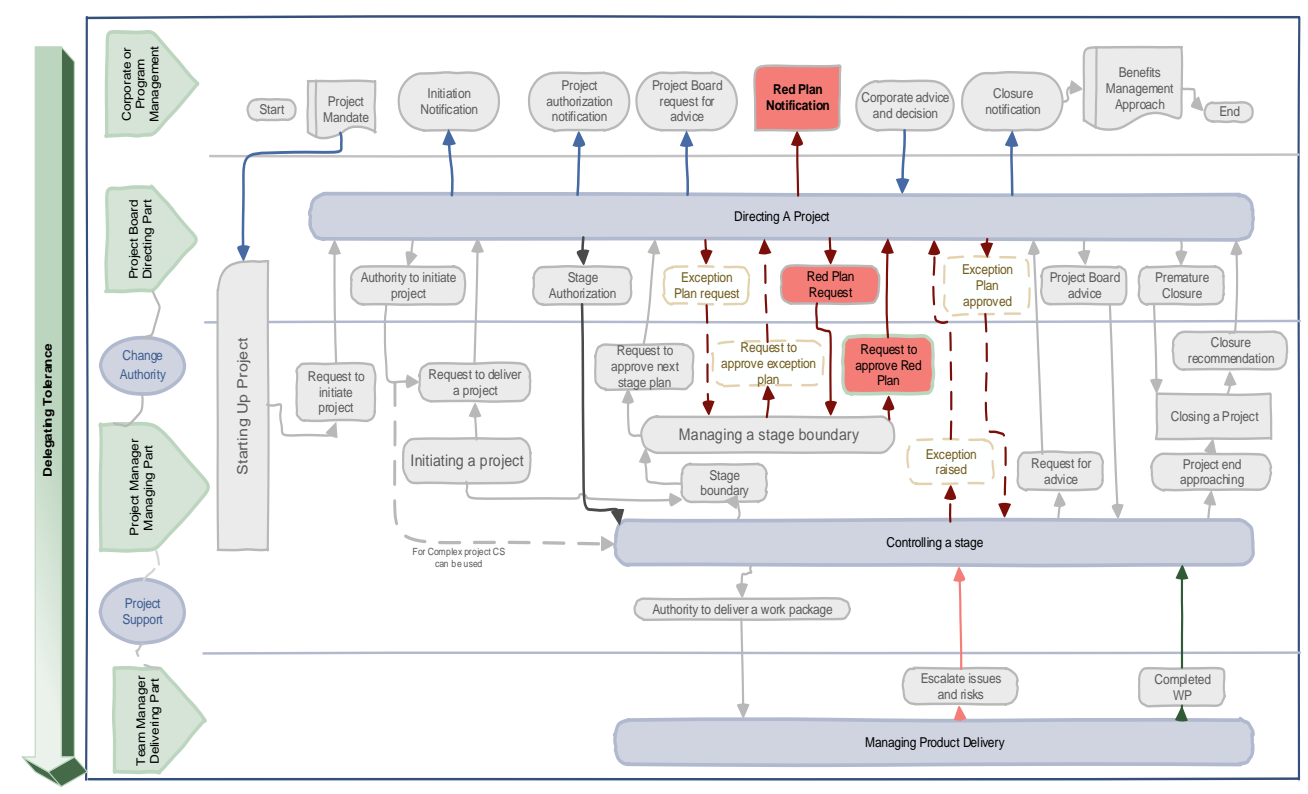

Fig 1.2

\section{Terms and Conditions to Apply RP}

One of the principles of PRINCE2 defines tailor to suit the project environment that depends on project complexity, size, importance, risk and capability. This principle helps to manage project with flexibility because too much limitations kill the initiative spirit, motivation and creativity in project team [7], [9], [10]. However, the consequences of Premature Closing Decision Situation (PCDS) are totally based on six variables like timescales, cost, quality, scope, benefits and risks. The proposed RP is suitable for the projects with following terms and conditions:

- Post-payment based projects

- If the PCDS is based on Time and Cost

- Tendering and Bidding based projects [6]

- If the Company/Organization have planned for long term business opportunities.

- Matter of Credibility for Company/Organization

Moreover, the most important term is to maintain rest of other performance targets like benefits quality, scope and risks.

\section{Methodology of Proposed Red Plan}

In this section, the objective is to develop a Red Plan (RP) for a project. The proposed plan evaluates the critical situation of PCDS (in terms of cost and time) and predicts the correct decision to reduce the total loss. As mentioned before, the purpose of the RP is to secure project when Project Board come on PCDS point. After Starting, project always take its own time and it is not easy to stop project or justify that an idea must wait [11-13].

In PRINCE2, Project Board have two options in critical situation (1) Exception Plan and other is (2) Decision for premature close of project. 
As discussed before, there are some terms and conditions to apply RP. The proposed RP methodology is the comparison between PCDS and project completion point in term of time and cost as shown in fig 1.3. Sometime, Project Board faces problem, for example, if tolerance limits break continuously and risk of threat accept level becomes high which directly effects on cost and time of the project. If the situation arises where Project Board has to take decision that project is no more profitable and need more investment, so they request to Project Manager to close the project. In such situation RP helps to identify and evaluate the loss if project suddenly closes and if project continues till completion.

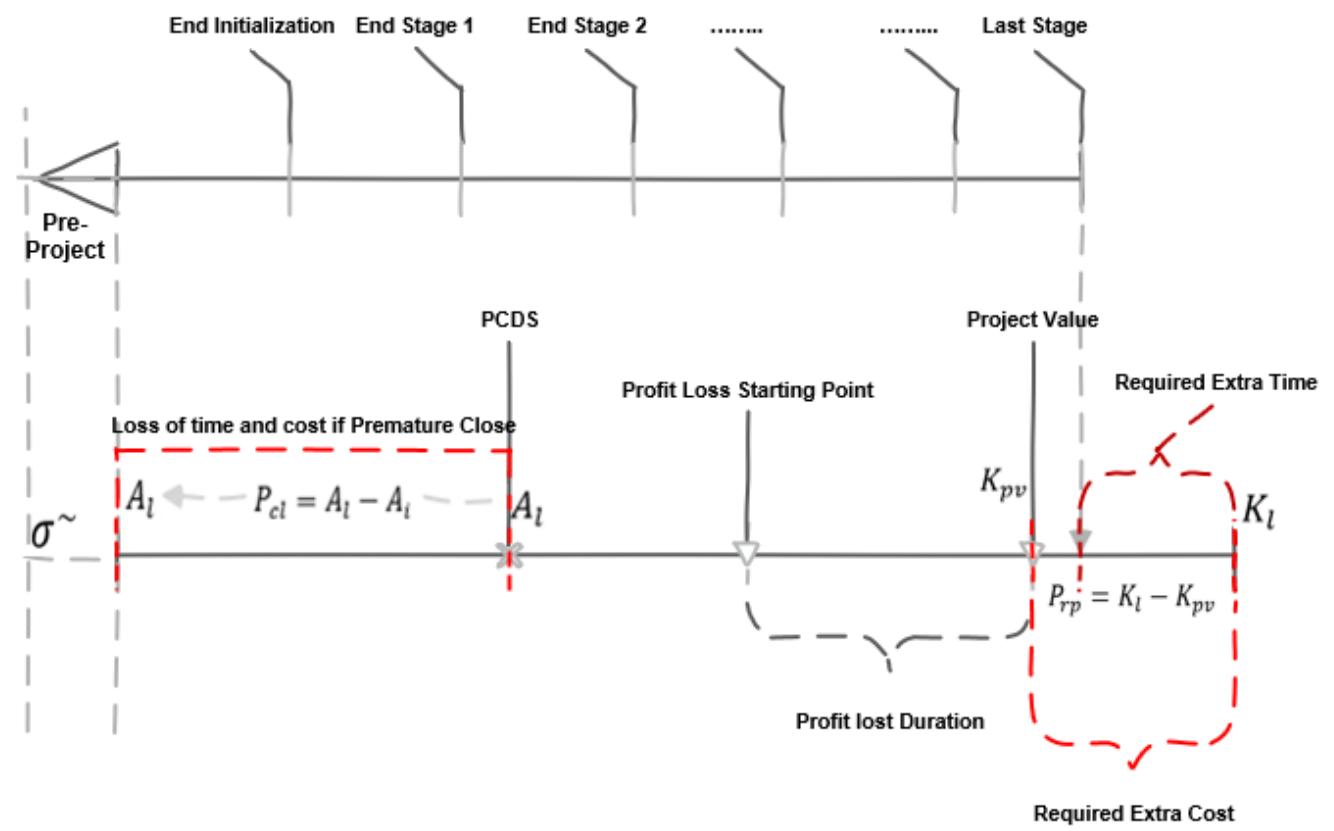

Fig 1.3

So, RP has been created at PCDS point and loss is calculated using (1),

$$
P_{c l}=A_{l}-A_{i}+\sigma^{\sim}
$$

hence $P_{c l}$ is the loss of cost in time till PCDS point. So, it describes the loss of cost per time from start $A_{i}$ to $A_{l}$ (PCDS) milestone while $\sigma^{\sim}$ denotes the loss of cost in pre-project duration as shown in figure 1.3.

$$
P_{r p}=K_{l}-K_{p v}
$$

here $P_{r p}$ has been evaluated using RP which explains the required extra cost as compared to estimated baselined cost (in business case) while $K_{p v}$ is the cost per time when cost equal to project value and $K_{l}$ is the cost at the time of project completion.

Condition A: $\quad P_{c l}>P_{r p}$ Continue and follow RP

Condition B: $\quad P_{c l}<P_{r p}$ Close the project

So, the conditions make the decision easy to take next step. 


\section{Results}

We have experienced and faces similar kind of situation as mentioned in terms and condition section. The idea of this paper has been described in below dummy short example. There are total six stages with initialization stage while pre-project depends on situation. If the project is part of program, then pre-project will not be considered. So, we have included pre-project part as individual project which is not part of the program as well as with post payment condition. In figure 1.4, parts "a" and " $b$ " have sketched from column " $A$ " and "B" of table 1 which shows: how normal project divert from its original position in term of cost and time (a to $b$ ).

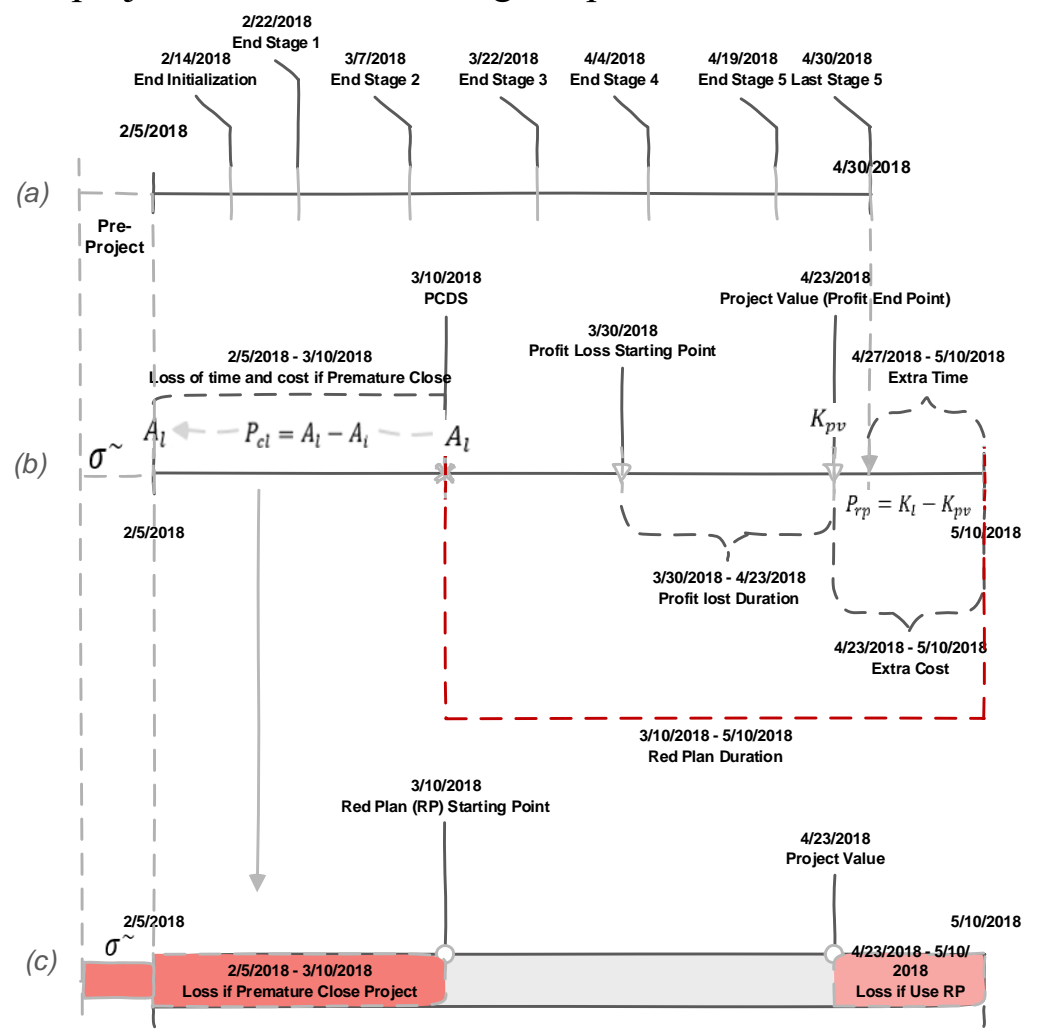

Fig 1.3

Furthermore, c part shows the significant and vivid picture of loss comparison by using red plan. In other words, red highlighted areas show that "what will be the loss if project sudden close and what will be loss if project continue". So, the loss if continue project is lower than project sudden close because of post payment condition. 
INTERNATIONAL CONFERENCE ON BUSINESS, MANAGEMENT AND FINANCE

UNITED KINGDOM | LONDON | March 7-9,2019

Table 1: Summary of project cost and time for each stage including other brief information

\begin{tabular}{|c|c|c|c|c|c|c|c|}
\hline \multirow{2}{*}{\begin{tabular}{|l|} 
\\
Project Process (End)
\end{tabular}} & \multicolumn{2}{|c|}{$\begin{array}{c}\text { (A): Estimated Time and } \\
\text { Cost }\end{array}$} & \multicolumn{3}{|c|}{ (B): Actual Time and Cost Due to Risk Happened } & \multicolumn{2}{|c|}{ (C): Difference Between (A) \& (B) } \\
\hline & Time (days) & Cost (USD) & Time (days) & Cost (USD) & & $\begin{array}{c}\text { Time } \\
\text { (Days) } \\
\text { difference }\end{array}$ & Cost (USD) \\
\hline Pre-Project & 5 & $\$ 4,000.00$ & 5 & $\$ 4,000.00$ & & 0 & $\$ 0.00$ \\
\hline Initialization & 7 & $\$ 5,000.00$ & 7 & $\$ 5,000.00$ & & 0 & $\$ 0.00$ \\
\hline Stage 1 & 6 & $\$ 5,000.00$ & 8 & $\$ 6,000.00$ & & 2 & $\$ 1,000.00$ \\
\hline Stage 2 (PCDS) & 10 & $\$ 4,000.00$ & 11 & $\$ 6,000.00$ & RP Start & 1 & $\$ 2,000.00$ \\
\hline Stage 3 & 10 & $\$ 5,000.00$ & 10 & $\$ 7,000.00$ & & 0 & $\$ 2,000.00$ \\
\hline Stage 4 & 7 & $\$ 2,000.00$ & 8 & $\$ 8,000.00$ & & 1 & $\$ 6,000.00$ \\
\hline Stage 5 & 10 & $\$ 3,000.00$ & 13 & $\$ 6,000.00$ & & 3 & $\$ 3,000.00$ \\
\hline Stage 6 with Closing & 6 & $\$ 4,000.00$ & 7 & $\$ 7,000.00$ & & 1 & $\$ 3,000.00$ \\
\hline Total & 61 & $\$ 32,000.00$ & 69 & $\$ 49,000.00$ & & 8 & $\$ 17,000.00$ \\
\hline
\end{tabular}

\begin{tabular}{|c|c|}
\hline Project Value & $\$ 41,000.00$ \\
\hline Estimated Profit & $\$ 9,000.00$ \\
\hline Loss of Cost If Premature Closure of Project & $\$ 21,000.00$ \\
\hline Time Loss If Premature Closure of Project & 31 Dyas \\
\hline Total Cost Evaluated by RP from PCDS & $\$ 28,000.00$ \\
\hline Total Time Evaluated by RP from PCDS & 38 Dyas \\
\hline Extra cost required over Project Value & $\$ 8,000.00$ \\
\hline Extra time required as compared to last estimated Project Plan & 8 Dyas \\
\hline
\end{tabular}

Basically, there are three main columns A, B and C in table 1. "A" column shows the part of real estimated/baseline project plan cost and time. B column shows deviation in time and cost due to risk happened before second stage while at end of second stage, RP has started. C column is the difference between A and B, in other words, it shows the further investment of time and cost in each stage.

So, we evaluated time and cost of the complete project in presence of continual risk in each stage from RP. As we can see in below fig 1.5, the PCDS point is at 21000 USD that mean, if project close then the loss of cost and time will be 21000 USD and 31 days respectively. If we follow the RP from point $A_{l}$ to $K_{l}$ dotted line, then we can see total cost and total time required to continue project is 28000 USD and 38 days respectively.

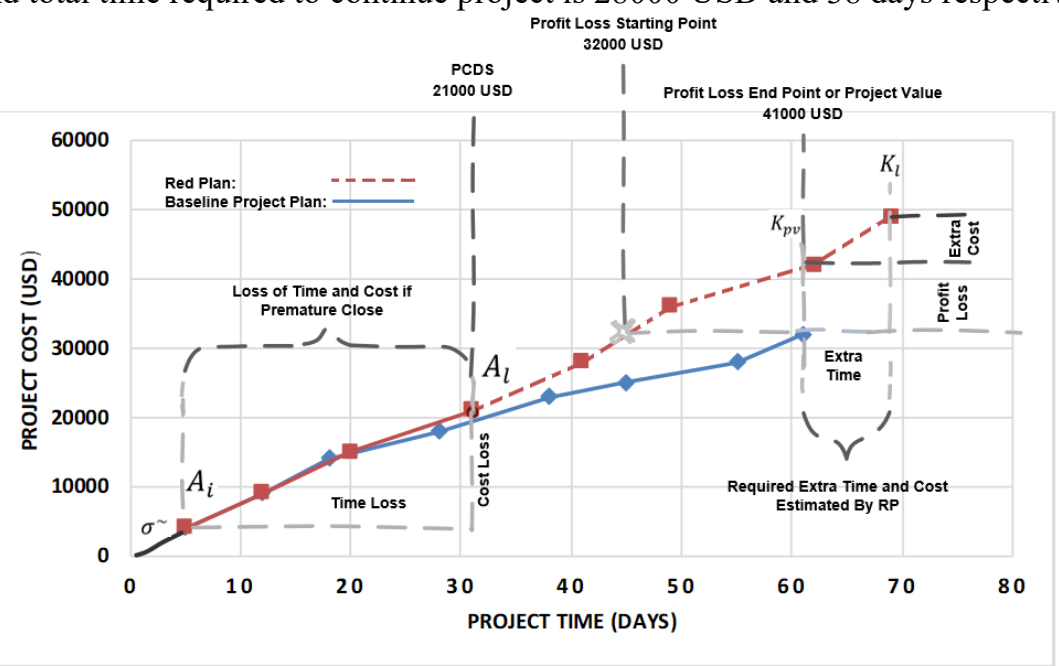

Fig 1.5

Moreover, with condition of post payment, as project value was 41000 USD and expenses reached to 49000 USD (Total cost before RP and After RP). So extra cost required as compared to baseline project plan is 8000 USD that is highlighted in the graph from $K_{p v}$ to $K_{l}$ milestone, in other words it is the extra loss/further investment after profit loss.

At last, we can see the loss difference between $K_{l}$ to $K_{p v}$ is lower than $A_{i}$ to $A_{l}$ including pre-project $\sigma^{\sim}$ as well. Eventually, in this scenario, condition A fulfilled, and loss comparison result has been mentioned in figure 1.4 part (c). 


\section{Conclusion}

In this paper, we proposed RP in PRINCE2 methodology. It gives best estimation and decision at critical situation to secure project. There can be a lot of reasons to close the project prematurely but the main concern of Executive from Project Board throughout the project is "Is the project value for money?" So, if project is predicted to be no more profitable then PCDS take place. Results from this study are expected to help Project Board/decision makers at PCDS that how to take decision to secure project in terms of loss comparison of cost and time. This methodology works under few terms and conditions that have described in section III. Sometimes, decision of premature closing of project on the bases of company profit can be good for short term but not good for long term business opportunities, for example it can be effect on future marketing and credibility of the company.

\section{References}

1. C. Jing-wu and Z. Xian, "PRINCE2 Based Project Management Maturity Model", International Conference on Management and Service Science (MASS 2010), pp. 1-4, August 2010.

2. M. Engwall and A. Jerbrant, "The resource allocation syndrome: the prime challenge of multi-project management," International Journal of Project Management, 2002.

3. N. Archer, F. Ghasemzadeh, "An integrated framework for project portfolio selection," International Journal of Project Management, 1999.

4. R. G. Cooper, S. J. Edgett, and E. J. Kleinschmidt, Portfolio Management for New Products. Reading, USA, Perseus Books, 1998.

5. Bentley, Colin. Prince2: a practical handbook. Routledge, 2012.

6. CFT, ADM. "CALL FOR TENDERS."

7. Nawrocki J., Olek L., Jasinski M., Paliświat B., Walter B., Pietrzak1 B.,Godek P. Balancing Agility and Discipline with XPrince, available athttp://www.xprince.pl/artykuly/05rise.pdf

8. PRINCE2 manual, Crown Copyright 2002.

9. Nawrocki, J., Jasinski, M., Olek, L., Lange, B. Pair Programming vs. Side-by-Side Programming. Proceedings of the European Software Process, Improvement and Innovation Conference. (2005).

10. Noble J., Marshall S., Marshall S., Biddle R., Less Extreme Programming. Available at http://crpit.com/ confpapers/ CRPITV30Noble.pdf

11. Gutierrez, Ernesto, et al. "Innovation and decision making: understanding selection and prioritization of development projects." Management of Innovation and Technology, 2008. ICMIT 2008. 4th IEEE International Conference on. IEEE, 2008.

12. O. Dawidson, "Project portfolio management - an organizing perspective," $\mathrm{Ph} . \mathrm{D}$. dissertation, Department and Faculty, Chalmers University of Technology, City, Sweden, 2006. E. F. McDonough III and F. C. Spital, "Managing Project Portfolios," Research Technology Management, Industrial Research Institute, 2003.

13. S. Elonen and K. A. Artto, "Problems in managing internal development projects in multi-projects environments," International Journal of Project Management, 2002. 